\title{
Article \\ Effect of Pd/ZnO Morphology on Surface Acoustic Wave Sensor Response
}

\author{
Dana Miu ${ }^{1}$, Izabela Constantinoiu ${ }^{1,2} \mathbb{C}$, Cornelia Enache ${ }^{1}$ and Cristian Viespe ${ }^{1, *(1)}$ \\ 1 Laser Department, National Institute for Laser, Plasma and Radiation Physics, Atomistilor 409, \\ RO-077125 Magurele, Romania; dana.miu@inflpr.ro (D.M.); izabela.constantinoiu@inflpr.ro (I.C.); \\ cornelia.sima@inflpr.ro (C.E.) \\ 2 Faculty of Applied Chemistry and Materials Science, University Politehnica of Bucharest, \\ RO-011061 Bucharest, Romania \\ * Correspondence: cristian.viespe@inflpr.ro
}

Citation: Miu, D.; Constantinoiu, I.; Enache, C.; Viespe, C. Effect of $\mathrm{Pd} / \mathrm{ZnO}$ Morphology on Surface Acoustic Wave Sensor Response. Nanomaterials 2021, 11, 2598. https:// doi.org/10.3390/nano11102598

Academic Editor: Noushin Nasiri

Received: 7 September 2021

Accepted: 29 September 2021

Published: 2 October 2021

Publisher's Note: MDPI stays neutral with regard to jurisdictional claims in published maps and institutional affiliations.

Copyright: (c) 2021 by the authors. Licensee MDPI, Basel, Switzerland. This article is an open access article distributed under the terms and conditions of the Creative Commons Attribution (CC BY) license (https:// creativecommons.org/licenses/by/ $4.0 /)$.

\begin{abstract}
Laser deposition was used to obtain Pd/ZnO bilayers, which were used as sensing layers in surface acoustic wave (SAW) sensors. The effect of laser deposition parameters such as deposition pressure, laser energy per pulse, laser wavelength or pulse duration on the porosity of the $\mathrm{Pd}$ and $\mathrm{ZnO}$ films used in the sensors was studied. The effect of the morphology of the Pd and $\mathrm{ZnO}$ components on the sensor response to hydrogen was assessed. Deposition conditions producing more porous films lead to a larger sensor response. The morphology of the $\mathrm{ZnO}$ component of the bilayer is decisive and has an influence on the sensor properties in the same order of magnitude as the use of a bilayer instead of a single $\mathrm{Pd}$ or $\mathrm{ZnO}$ layer. The effect of the Pd film morphology is considerably smaller than that of $\mathrm{ZnO}$, probably due to its smaller thickness. This has implications in other bilayer material combinations used in such sensors and for other types of analytes.
\end{abstract}

Keywords: $\mathrm{ZnO}$; Pd; morphology; pulsed laser deposition; hydrogen; surface acoustic wave; sensor; bilayer; nanoporous

\section{Introduction}

Due to its energy potential, hydrogen is the initiator of a new generation of fuel. Compared to fossil fuels, the environmental impact of hydrogen is low [1,2]. Hydrogen is used in fields such as aerospace programs, the automotive industry, pharmaceutics, the chemical industry, metallurgy, etc. [3-5]. However, the use of hydrogen also requires strict safety measures, because, at concentrations over $4 \%$, hydrogen becomes flammable [6,7]. Thus, because it is used on a large scale, it is necessary to develop methods to prevent disasters. In order to achieve this, sensors for the detection of hydrogen at low concentrations remain a safe and accessible method.

Surface acoustic wave (SAW) sensors are notable due to their very high sensitivity, short response and recovery times, the possibility of wireless operation, small size and ease of fabrication [8,9]. The principle of operation of this type of sensor is based on the transformation of an electrical signal into a mechanical wave that travels at the surface of the sensor, which includes a sensitive area. When the gas molecules to be detected appear at the level of the sensitive area, the mechanical waves are disturbed, thus changing the oscillation frequency. The surface acoustic wave is then transformed back into an electrical signal, with an output oscillation frequency shifted from the input one. The frequency shift is mainly caused by the mass or acoustoelectric changes that take place at the level of the sensitive layer in the presence of gas molecules [10]. SAW sensors are used both for the detection of hydrogen and for the detection of volatile organic compounds, ammonia, hydrogen sulfide or other toxic or explosive gases [8,11-14].

One of the main factors that affects their performance is the sensitive material of the sensor. Depending on the type of gas to be detected, both the type and the morphology 
of the sensitive material are important. For the detection of hydrogen, SAW sensors with different types of sensitive layers have been developed: metal oxide semiconductors $\left(\mathrm{ZnO}, \mathrm{SnO}_{2}, \mathrm{TiO}_{2}\right)$ [15-18], metals ( $\mathrm{Pd}$ and $\left.\mathrm{Pt}\right)$ [19] and composite materials $[9,13,20]$. The morphology of these materials has a very important role in ensuring the interaction of gas molecules with the sensitive film over a large surface. Therefore, the synthesis of sensitive layers with optimal porosity is pursued.

Pulsed laser deposition (PLD) is one of the most efficient methods for the synthesis of thin films. It allows the deposition of a wide variety of materials with the advantage of maintaining their stoichiometry [21]. It is a reproducible method, which allows deposition at low temperatures and ensures purity $[22,23]$. In addition, due to the possibility to vary a wide range of deposition parameters, different types of morphologies can be obtained, which is a very important aspect for the field of sensors [16]. Such important deposition parameters are: the gas pressure inside the deposition chamber, the wavelength and repetition rate of the laser, the distance between the target and the substrate, the number of pulses and pulse duration and the substrate temperature [24].

In a previous paper on SAW sensors with $\mathrm{Pd} / \mathrm{ZnO}$ bilayers, we proved that the bilayer leads to better sensor properties than single $\mathrm{Pd}$ or $\mathrm{ZnO}$ layers having the same total thickness [25]. In the present research, we varied the morphology (porosity) of the $\mathrm{Pd}$ and $\mathrm{ZnO}$ layers in order to assess the effect on the response of the SAW sensors. The morphology of the $\mathrm{Pd}$ and $\mathrm{ZnO}$ layers was modified by varying various laser deposition parameters, such as pressure, laser power and wavelength, number of pulses and pulse duration. As mentioned, the morphology of the sensitive films, especially the porosity, has a large effect on the response of the SAW sensor to gases.

\section{Materials and Methods}

$\mathrm{ZnO}$ and $\mathrm{Pd}$ layers and $\mathrm{Pd} / \mathrm{ZnO}$ bilayers were deposited onto Si and ST-X quartz substrates using PLD. A Nd-YVO laser (Lumera Rapid, Kaiserslautern, Germany) with 10 ps pulse duration was used for the depositions, at various power levels $(0.1 ; 0.2 ; 0.3 \mathrm{~W})$. The laser beam was focused using a $320 \mathrm{~mm}$ lens onto the surface of the targets placed in a vacuum chamber equipped with a gas pressure controller (MKS 600, Munchen, Germany) and a mass-flow control system (MKS multigas 647, Munchen, Germany). The ZnO films were deposited in oxygen in order to ensure correct stoichiometry. The Pd films were deposited in argon. Both in the case of $\mathrm{ZnO}$ and of $\mathrm{Pd}$, the deposition pressures used were between 100 and 700 mTorr. The ablated target material was deposited onto substrates placed $4 \mathrm{~cm}$ from the targets, parallel to the target surface. In order to avoid target erosion, which leads to unfavorable film morphology, the targets were subjected to continuous movement during deposition by means of computer-controlled $x-y$ tables. More details of the deposition system can be found in [17]. Two laser emission wavelengths were used: $532 \mathrm{~nm}$ and $1.06 \mu \mathrm{m}$. Most of the films were deposited using a $10 \mathrm{kHz}$ laser repetition rate. In order to ascertain the possible effect of the laser repetition rate on the deposition, some depositions were made at a $50 \mathrm{kHz}$ repetition rate. Some depositions were also made using a Nd-YAG laser with ns pulse durations (EKSPLA NL301HT, Ekspla, Vilnius, Lithuania) to determine the effect of pulse durations on the deposited film morphology.

Thin film monolayers and bilayers were deposited onto Si substrates for scanning electron microscopy (SEM) analysis. In the case of the bilayers, the Pd film component was deposited with a smaller number of pulses, being thinner than the $\mathrm{ZnO}$ component. The $\mathrm{Pd}$ layer must be thinner in the sensor, because its role is to dissociate the $\mathrm{H}_{2}$ molecule, so that the resulting $\mathrm{H}$ atoms have larger mobility, increasing their detection after diffusion into the $\mathrm{ZnO}$ component [26]. FEI QUANTA SEM (Hillsboro, OR, USA) for surface analysis and Thermo Scientific Apreo SEM (Thermo Scientific, Waltham, MA, USA) for cross-section analysis were used to study the dependence of the film morphology on deposition parameters including deposition pressure, laser power, laser wavelength, number of ablation pulses and pulse repetition rate. X-ray diffraction analysis of the $\mathrm{ZnO}$ films deposited in various conditions was performed using a Bruker D2 Phaser (benchtop) (Billerica, Mass., 
USA). The roughness of films deposited in various conditions was determined using a SURFCOM 180 A (Tokyo Seimitsu, Tokyo, Japan) profilometer.

In order to establish the dependence of the SAW sensor properties on the morphology of the $\mathrm{ZnO}$ and $\mathrm{Pd}$ thin films, components of the sensitive bilayer, $\mathrm{ZnO}$ layers and $\mathrm{Pd} / \mathrm{ZnO}$ bilayers were deposited onto SAW sensor substrates. The SAW sensors were of the delay line type and consisted of two port resonators with 50 electrode pairs and a periodicity of $11 \mu \mathrm{m}$. Interdigital transducers (IDTs) are obtained using standard photolithographic techniques on ST-X quartz substrates. IDTs have a periodicity of $45 \mu \mathrm{m}$ and a $2500 \mu \mathrm{m}$ wide acoustic aperture, and consist of a $10 \mathrm{~nm}$ chromium layer, which has good adherence to the quartz substrate, on top of which there is a $150 \mathrm{~nm}$ thick gold layer [27]. The thin film depositions onto the sensor substrates were made through a custom mask that delimited the sensing film to the area between the two electrode pairs. In the case of the sensors, the $\mathrm{ZnO}$ layers were deposited in $2 \mathrm{~h}$ at $10 \mathrm{kHz}$, while the Pd layers were thin, deposited in $2^{\prime} 23^{\prime \prime}$ also at $10 \mathrm{kHz}$.

The sensors were characterized, as shown in Figure 1, using a CNT-91 Pendulum counter analyzer (Spectracom Corp, Rochester, NY, USA) with Time View 3 software (Pendulum Instruments, Banino, Poland). The sensor responses (frequency shifts) for various hydrogen concentrations between 0.2 and $2 \%$ were determined in a total gas flow rate maintained constant at $0.5 \mathrm{~L} / \mathrm{min}$ in all cases. The various concentrations were obtained by combining a hydrogen gas mixture $\left(2 \% \mathrm{H}_{2} / 98 \%\right.$ synthetic air) with pure synthetic air, using a system that included mass-flow meters and controllers. For more details on the experimental setup used for sensor characterization, see [28].

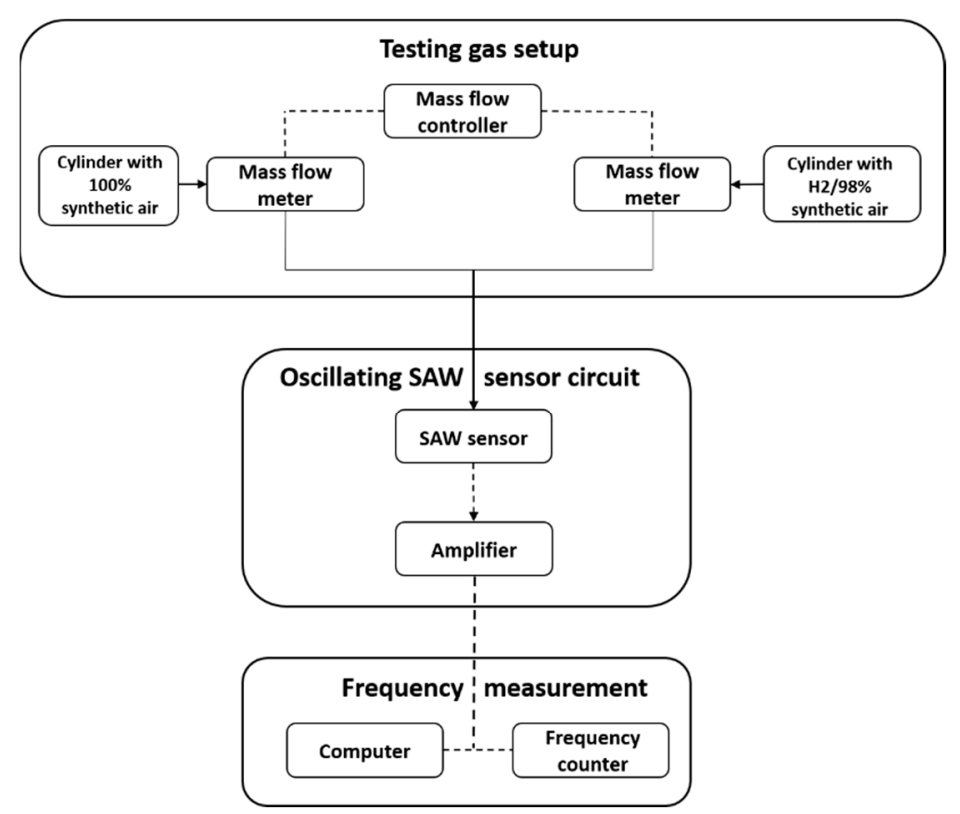

Figure 1. Experimental setup for SAW sensors' frequency shift measurements for hydrogen detection.

\section{Results and Discussion}

\subsection{Film Morphology}

\subsection{1. $\mathrm{ZnO}$ Films}

The dependence of the morphology of $\mathrm{ZnO}$ films deposited onto $\mathrm{Si}$ substrates on various deposition parameters was determined based on SEM images.

The effect of deposition pressure on the morphology of the $\mathrm{ZnO}$ films is illustrated in Figure 2. 

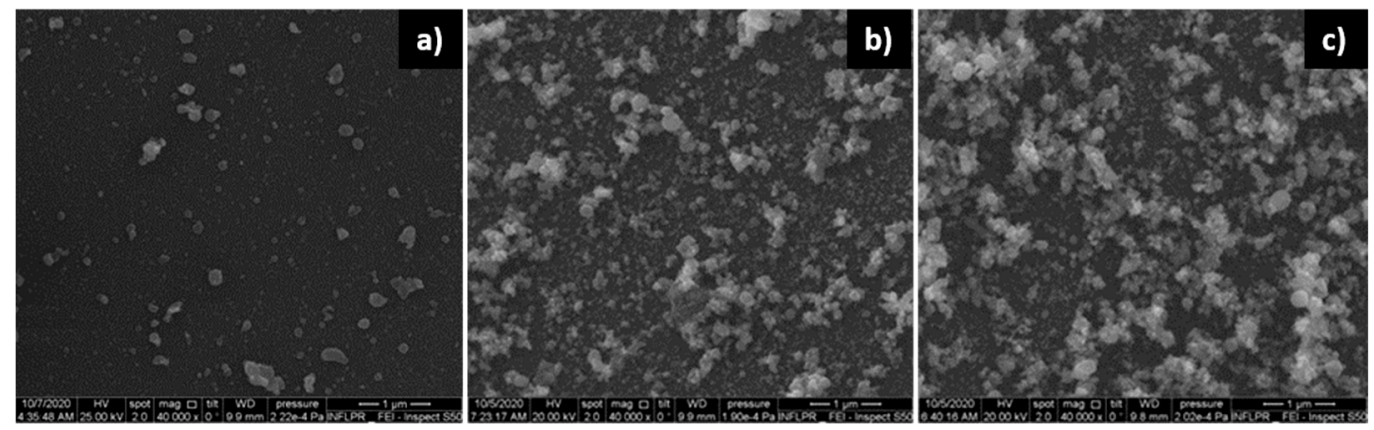

Figure 2. SEM images of $\mathrm{ZnO}$ films deposited using a ps laser, a wavelength of $532 \mathrm{~nm}$, a power of $0.2 \mathrm{~W}$ and a pulse repetition rate of $10 \mathrm{kHz}$. The $\mathrm{O}_{2}$ pressure used was (a) 100 mTorr; (b) 400 mTorr; (c) 700 mTorr.

Of the oxygen pressures used, the $\mathrm{ZnO}$ film deposited in $700 \mathrm{mTorr}_{2}$ was the most porous, as the SEM cross-section images confirm (Figure 3). Although the images of the $\mathrm{ZnO}$ films deposited using 400 and 700 mTorr are qualitatively similar, the film deposited in 700 mTorr is clearly more porous. On the other hand, the films obtained in 100 and 400 mTorr are qualitatively different, as evidenced by Figure 2a,b. A comparison of the surfaces of the $\mathrm{ZnO}$ films deposited in 100 and $700 \mathrm{mTorr}_{2}$ was made using the Image $\mathrm{J}$ software [29]. The nanoparticles on the surface of the film have a mean diameter of approximately $21 \mathrm{~nm}$ (determined by measuring over 100 nanoparticles) in both cases. In the case of the film deposited in $700 \mathrm{mTorr}$, this is the dimension of the separated nanoparticles, not that of the agglomerations that form the porous nanostructures visible in Figure 2c, and in the cross-section in Figure 3. The difference between these two SEM images consists of the percentage of the area covered by the porous formations of nanoparticle agglomerations. In the case of the film deposited at high pressure, approximately $40 \%$ of the area of the surface in Figure 2c is covered by these formations, while at low pressures (Figure 2a), only approximately $6 \%$ of the surface consists of nanoparticle agglomerations. The larger porosity of the films deposited at higher pressures was confirmed by measurements of its surface roughness using a profilometer. The arithmetical mean deviation $R_{a}$ and the root mean square deviation of the profile $\mathrm{R}_{\mathrm{q}}$ of the $\mathrm{ZnO}$ film deposited using $1.06 \mu \mathrm{m}$ radiation in $700 \mathrm{mTorr} \mathrm{O}_{2}$ were found to be 21.00 and $26.67 \mathrm{~nm}$, respectively. In the case of a film deposited using the same wavelength but in $100 \mathrm{mTorr}, \mathrm{R}_{\mathrm{a}}=15.67 \mathrm{~nm}$ and $\mathrm{R}_{\mathrm{q}}=20.33 \mathrm{~nm}$. As can be observed in Figure 3, the large porosity of the film implies that the thickness of the film is non-uniform. The average thickness of the film in Figure 3, which was deposited in the same conditions as films used in SAW sensors, is approximately $850 \mathrm{~nm}$. It should be noted that we did not attempt to use higher deposition pressures since they lead to films that are unstable on the substrate surface, their adherence being poor.

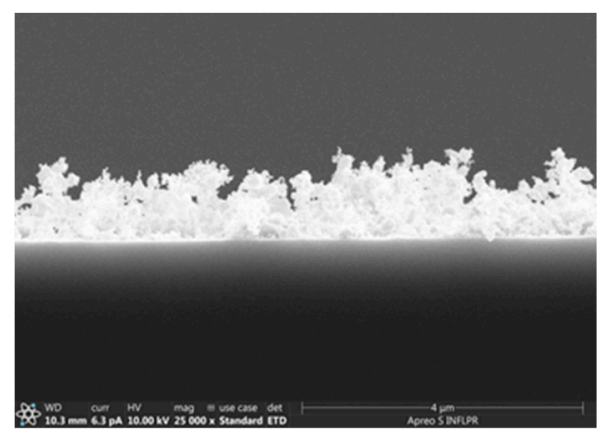

Figure 3. Cross-section SEM image of a $\mathrm{ZnO}$ film deposited in $2 \mathrm{~h}$ at a repetition rate of $10 \mathrm{kHz}$, a wavelength of $532 \mathrm{~nm}$, using a laser power of $0.2 \mathrm{~W}$, in $700 \mathrm{mTorr}_{2}$.

The fact that higher deposition pressures lead to increased film porosity can be explained through the hydrodynamic effects of the interaction between the laser-ablated species and the ambient gas at relatively high pressures. These effects lead to a pronounced 
slowing of the species in the ablation plasma. In these conditions, the ablated species are confined in the target-substrate region by the interaction with the gas molecules, the plasma density increases, and increased collisions between the ablated species lead to nucleation in the gas phase, with the formation of relatively slow nanoparticles in the target-substrate region [30-33].

This pressure dependence of the film morphology should be reflected in the properties of the sensors, since it is known that more porous films lead to better sensor responses [16]. We therefore measured the sensing properties of SAW sensors that incorporate $\mathrm{ZnO}$ layers deposited with 100 and 700 mTorr, in order to ascertain the role of the porosity of the $\mathrm{ZnO}$ component of the bilayer on the sensor response.

The morphology of the films changes as the thickness increases, as has been observed in other cases when depositions are made at high pressures [25,27]. The dependence of morphology on thickness is illustrated by the SEM images of the surfaces of $\mathrm{ZnO}$ films deposited in $2 \mathrm{~h}$ and $3 \mathrm{~h}$ (Figure $4 \mathrm{a}, \mathrm{b}$, respectively) using a laser wavelength of $1 \mu \mathrm{m}$, a repetition rate of $10 \mathrm{kHz}$ and a deposition pressure of $700 \mathrm{mTorr} \mathrm{O}_{2}$. As has been previously observed, the morphology of the film varies with the number of pulses [34]. The morphology of the films is not uniform over their entire thickness, with the films becoming more porous as the number of pulses increases. Films were not deposited with a larger number of pulses, since the acoustic wave attenuation is too high when the sensitive film is too thick.

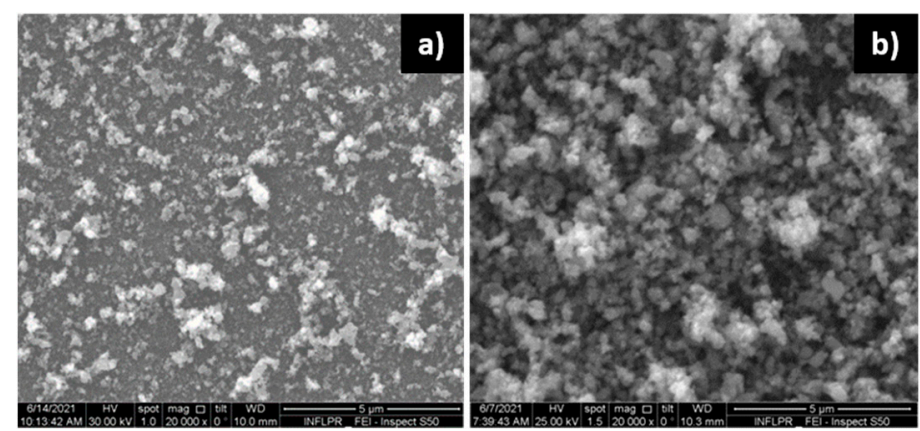

Figure 4. SEM images of $\mathrm{ZnO}$ films deposited using a laser wavelength of $1 \mu \mathrm{m}$, at a power of $0.2 \mathrm{~W}$ and a repetition rate of $10 \mathrm{kHz}$, in $700 \mathrm{mTorr}_{2}$, using (a) $2 \mathrm{~h}$ deposition time; (b) $3 \mathrm{~h}$ deposition time.

The $\mathrm{ZnO}$ films also become more porous with increasing laser power for powers between 0.1 and $0.3 \mathrm{~W}$. The laser pulse repetition rate being the same in all cases $(10 \mathrm{kHz}$ in the case discussed here), the energy per pulse increases with increasing power, being of the order of tens of $\mu \mathrm{J}$. The differences in morphology can probably also be explained by the variation in thickness with power.

Regarding the dependence of the film morphology on wavelength, the difference between $\mathrm{ZnO}$ films deposited at $532 \mathrm{~nm}$ and $1 \mu \mathrm{m}$ is not considerable (Figure $5 \mathrm{a}, \mathrm{b}$ ). However, at a large scale, the films deposited at $532 \mathrm{~nm}$ seem to have a larger density of porous formations than the ones deposited at $1.06 \mu \mathrm{m}$ (Figure 5c,d). This will be reflected in the properties of the sensors into which they are incorporated, as will be discussed later. 


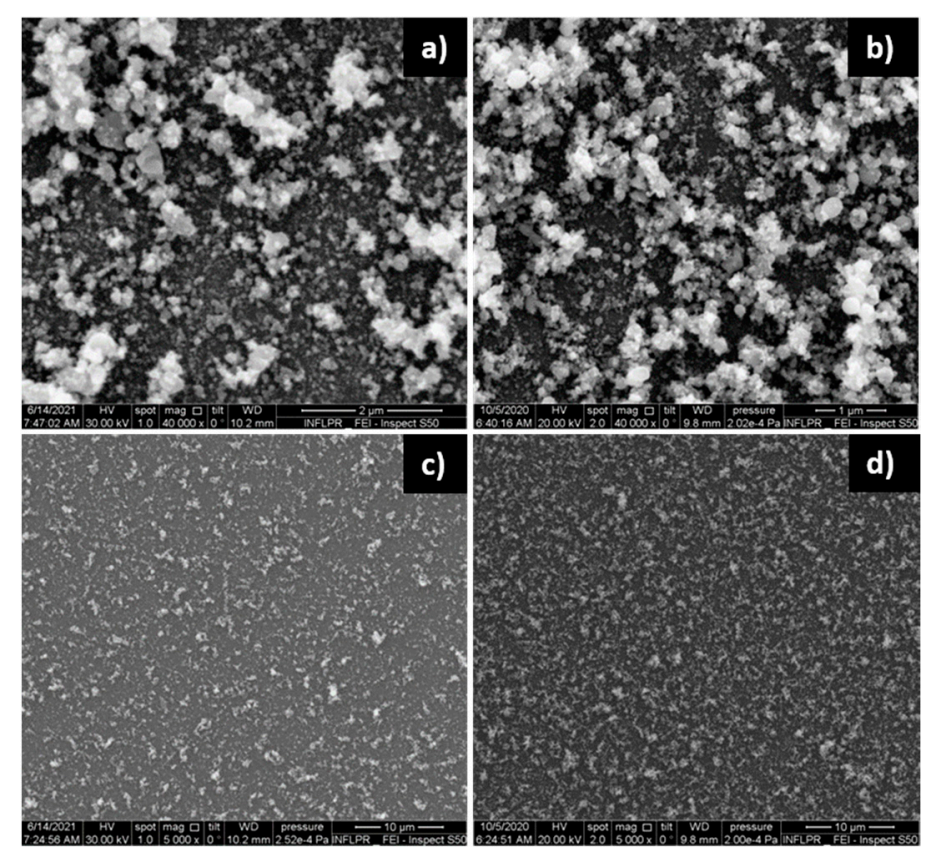

Figure 5. SEM images, at two magnifications, of $\mathrm{ZnO}$ films deposited in $700 \mathrm{mTorr} \mathrm{O}_{2}$ with $0.2 \mathrm{~W}$ using $1.06 \mu \mathrm{m}(\mathbf{a}, \mathbf{c})$ and $532 \mathrm{~nm}(\mathbf{b}, \mathbf{d})$ laser emission wavelength.

$\mathrm{ZnO}$ films were deposited at two different laser repetition rates: $10 \mathrm{kHz}$, as used in the rest of the depositions with the ps laser, and $50 \mathrm{kHz}$. By varying the average power of the laser correspondingly ( $0.2 \mathrm{~W}$ for $10 \mathrm{kHz}$ and $1 \mathrm{~W}$ for $50 \mathrm{kHz})$, the energy per pulse can be maintained in both cases, namely $20 \mu \mathrm{J} /$ pulse. In this domain, the repetition rate had no effect on the morphology of the film. It should be noted that $50 \mathrm{kHz}$ was the limit of the domain attainable, since, although larger differences in repetition rates were possible, the average power necessary to ensure the same energy/pulse could not be reached.

As is visible in Figure 6, depositions of $\mathrm{ZnO}$ films using a laser with ps pulse durations led to considerably more porous $\mathrm{ZnO}$ layers than those with a ns laser. However, comparison between the effects of laser pulse duration is difficult due to the large differences that exist in other parameters: energy/pulse and pulse repetition rates. The energy per pulse is approximately $30 \mu \mathrm{J}$ per pulse for the ps laser and $75 \mathrm{~mJ} /$ pulse for the ns laser, while the pulse repetition rate is $10 \mathrm{kHz}$ and $10 \mathrm{~Hz}$, respectively, which means a difference of three orders of magnitude. The differences in average and peak powers are, however, not particularly large: $0.3 \mathrm{~W}$ average power and $7.5 \times 10^{6} \mathrm{~W}$ peak power for $\mathrm{ps}$, and $0.7 \mathrm{~W}$ average power and $13 \times 10^{6} \mathrm{~W}$ peak power for the ns laser. The difference is therefore, in this case, only a factor of around two. Regardless of the difficulty of comparing the effects of the two lasers, it is possible to state that from a practical standpoint, with the ps laser, it is easier to obtain porous $\mathrm{ZnO}$ films than with the ns laser. At the $532 \mathrm{~nm}$ emission wavelength, the ns laser does not produce porous structures, even at the relatively high deposition pressure of $700 \mathrm{mTorr}$, while the ps laser produces porous structures even at 400 mTorr. 


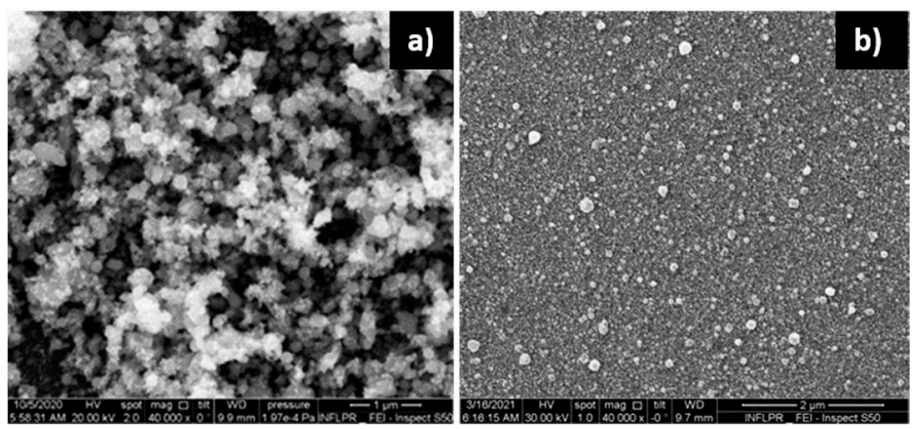

Figure 6. SEM images of $\mathrm{ZnO}$ films deposited in $700 \mathrm{mTorr}_{2} \mathrm{O}_{2}$ and a wavelength of $532 \mathrm{~nm}$ using (a) a ps laser with $0.3 \mathrm{~W}$ operating at $10 \mathrm{kHz}$ repetition rate; (b) a ns laser with $75 \mathrm{~mJ} /$ pulse operating at $10 \mathrm{~Hz}$ repetition rate.

$\mathrm{XRD}$ analysis of the $\mathrm{ZnO}$ films shows that no $\mathrm{Zn}$ lines are present, indicating correct $\mathrm{ZnO}$ stoichiometry. A crystallite size of $48 \mathrm{~nm}$ was determined by applying the Scherrer formula to the (101), (002) and (100) peaks of $\mathrm{ZnO}$ (according to diffraction pattern 2107059) present in the diffraction data obtained for a film deposited using IR radiation, in $700 \mathrm{mTorr}_{2}$.

\subsubsection{Pd Films}

In the case of Pd thin films, the dependence on pressure, laser power and number of pulses was investigated, and a comparison of film morphology obtained with the two different laser wavelengths was made.

As in the case of $\mathrm{ZnO}$, the porosity of the Pd films increases with deposition pressure. Figure 7 presents the surfaces of Pd thin films deposited in $30^{\prime}$ at $10 \mathrm{kHz}$. At this number of pulses, the surface of the layer deposited in $700 \mathrm{mTorr}$ Ar appears slightly more porous than the one deposited in 100 mTorr. A cross-section SEM image reveals the large porosity of the Pd thin film deposited in $700 \mathrm{mTorr}$. As in the case of $\mathrm{ZnO}$, the porosity of the film leads to large variations in the local film thickness across its surface. We estimate that the thickness of the thin Pd film used in the sensors is approximately $25 \mathrm{~nm}$.
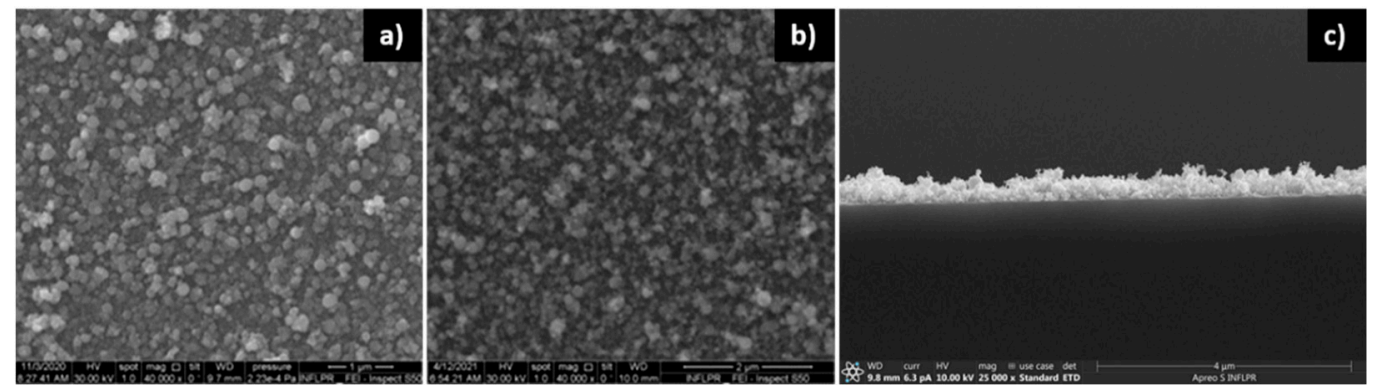

Figure 7. Pd thin films deposited at $10 \mathrm{kHz}$ in $30^{\prime}$ using the $532 \mathrm{~nm}$ laser radiation of a ps laser, and an average power of 0.2 W. (a) in 100 mTorr Ar; (b) in 700 mTorr Ar; (c) cross-section of film deposited in 700 mTorr Ar.

At the smaller number of pulses used to deposit the thin Pd layer in the SAW sensors $\left(2^{\prime} 23^{\prime \prime}\right.$ at $\left.10 \mathrm{kHz}\right)$, the difference between layers deposited at 100 and $700 \mathrm{mTorr}$ is not visible in the SEM images. As we will discuss in the section describing the sensor properties, however, some difference between the sensors comprising thin Pd layers deposited at 100 and $700 \mathrm{mTorr}$ does exist in the frequency shift produced in the presence of $\mathrm{H}_{2}$. As we have previously mentioned, the Pd component of the sensitive film bilayer of the SAW sensor is thinner than the $\mathrm{ZnO}$ layer, because its main role is to dissociate the hydrogen molecules, thereby increasing the mobility (diffusion) of the detected species into the sensing layer, which leads to an increase in the sensor's sensitivity [26]. Pd is therefore deposited with a smaller number of pulses. Figure 8 presents SEM images of the surfaces of Pd thin films deposited with different pulse numbers. 

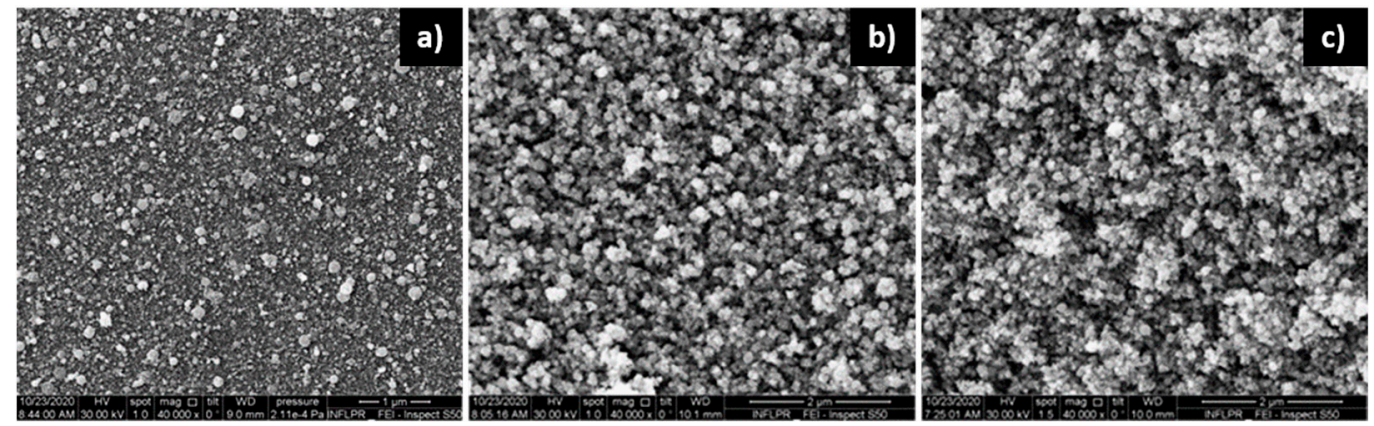

Figure 8. Pd films deposited at $10 \mathrm{kHz}$ with a ps laser with $0.3 \mathrm{~W}$ and $532 \mathrm{~nm}$, in (a) $2^{\prime} 23^{\prime \prime}$; (b) $30^{\prime}$; (c) 2 h. The deposition pressure was 400 mTorr Ar.

Regarding the dependence on laser power, visible differences only appear at high deposition pressure (700 mTorr). As seen in Figure 9, the porosity increases with laser power. As is the case with $\mathrm{ZnO}$, this is due to the increase in film thickness with laser power.
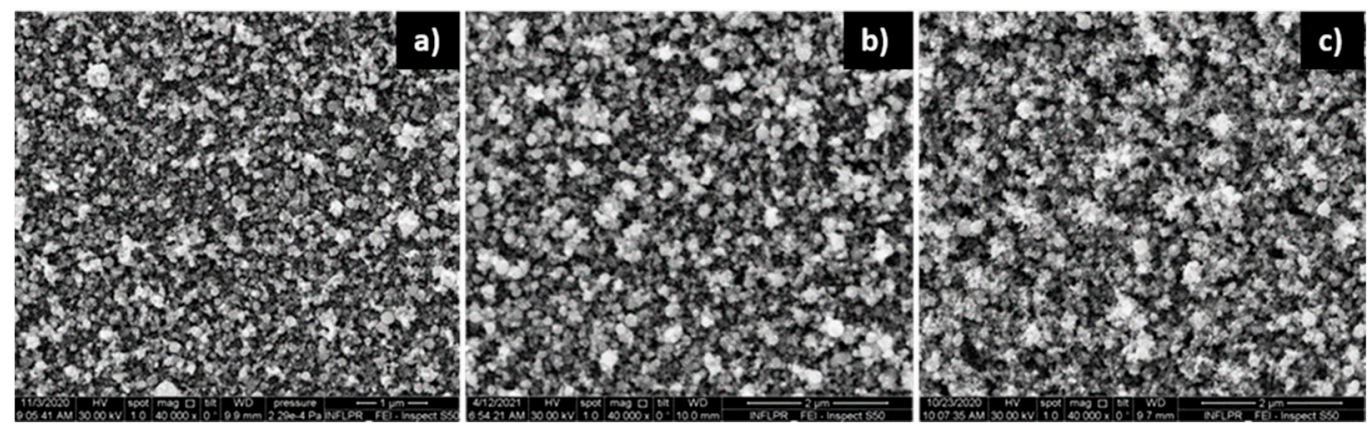

Figure 9. SEM images of the Pd thin film surface. Films were deposited in 700 mTorr Ar with a ps laser, using $532 \mathrm{~nm}$ radiation, at $10 \mathrm{kHz}$, in $30^{\prime}$, using an average power of (a) 0.1 ; (b) $0.2 \mathrm{~W}$; (c) $0.3 \mathrm{~W}$.

\subsection{3. $\mathrm{Pd} / \mathrm{ZnO}$ Bilayer}

SEM images of the bilayer surface (the surface of Pd deposited on top of the $\mathrm{ZnO}$ ) were obtained for the same deposition conditions as those used for the SEM sensors. In the case of $\mathrm{ZnO}$ deposited in $700 \mathrm{mTorr} \mathrm{O}_{2}$, there is no clear difference between the bilayers with Pd deposited in 100 mTorr Ar, those deposited in 700 mTorr Ar or the surface of the $\mathrm{ZnO}$ layer only, as is visible, for example, in Figure 10. Similar results were obtained for all the cases investigated, indicating that the morphology of the relatively thin Pd layer does not affect the morphology of the bilayer surface. This is confirmed by the EDAX mapping results of the bilayer surface. The distribution of the Pd on the surface of the bilayer is the same for Pd layers deposited in 100 and $700 \mathrm{mTorr} \mathrm{Ar}$, as well as for both the $532 \mathrm{~nm}$ laser wavelength and the $1.06 \mu \mathrm{m}$ wavelength. EDAX also confirms the fact that the $\mathrm{ZnO}$ is deposited more uniformly across the surface of the sensitive thin film when IR laser radiation is used, and it presents areas of larger $\mathrm{Zn}$ and $\mathrm{O}$ concentrations in the case of the $532 \mathrm{~nm}$ wavelength. These areas of larger concentration correspond to the porous density formations discussed in relation to Figure $5 \mathrm{~d}$. The morphology of the bilayer is therefore practically determined by that of the underlying $\mathrm{ZnO}$ layer. EDAX maps can be found in the Supplementary Material in Figure S1. 

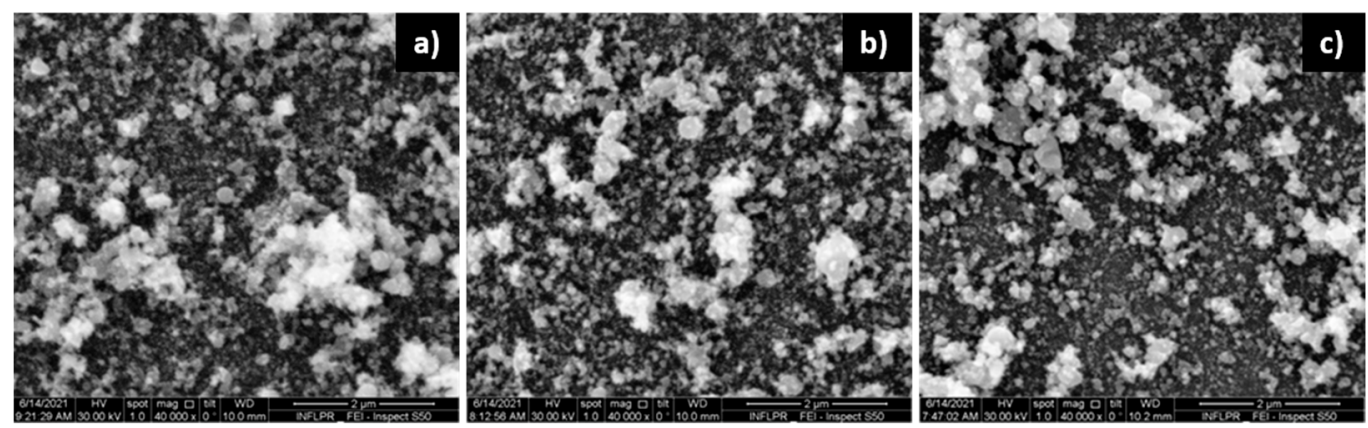

Figure 10. SEM images of (a) Pd/ZnO bilayer deposited in $2^{\prime} 23^{\prime \prime} / 2 \mathrm{~h}$ with $10 \mathrm{kHz}$, using $0.2 \mathrm{~W}$ laser power at a wavelength of $1.06 \mu \mathrm{m}$. The Pd layer is deposited in $100 \mathrm{mTorr}$ Ar, and the ZnO layer in $700 \mathrm{mTorr}_{2}$; (b) same as (a), but the Pd layer deposited in 700 mTorr Ar; (c) ZnO layer only deposited in the same conditions as in (a,b).

\subsection{Sensor Properties}

The response to hydrogen of SAW sensors having sensitive layers with $\mathrm{Pd} / \mathrm{ZnO}$ bilayers deposited in different conditions, as well as single $\mathrm{ZnO}$ layers, was determined. Table 1 gives the deposition parameters used to obtain the sensitive layers for the sensors that were tested. All of the sensitive layers were deposited using the laser with ps pulse durations (which leads to more porous films) using $10 \mathrm{kHz}$ and a power of $0.2 \mathrm{~W}$. The $\mathrm{ZnO}$ layers were deposited in $2 \mathrm{~h}$, and the Pd layers in $2^{\prime} 23^{\prime \prime}$.

Table 1. Conditions for deposition of the components of the sensitive films for the sensors that were measured. Sensors S5, S5 IR and S6 IR have a sensitive layer consisting in a single $\mathrm{ZnO}$ layer.

\begin{tabular}{cccc}
\hline Sensor & $\begin{array}{c}\text { Deposition Wavelength } \\
(\mathbf{n m})\end{array}$ & $\begin{array}{c}\mathbf{O}_{2} \text { Pressure-ZnO Deposition } \\
(\mathbf{m} \text { Torr) }\end{array}$ & $\begin{array}{c}\text { Ar Pressure-Pd Deposition } \\
(\mathbf{m} \text { Torr) }\end{array}$ \\
\hline S1 & 532 & 100 & 100 \\
S2 & 532 & 100 & 700 \\
S3 & 532 & 700 & 100 \\
S4 & 532 & 700 & 700 \\
S5 & 532 & 100 & - \\
S1 IR & 1064 & 100 & 100 \\
S2 IR & 1064 & 100 & 700 \\
S3 IR & 1064 & 700 & 100 \\
S4 IR & 1064 & 700 & 700 \\
S5 IR & 1064 & 100 & - \\
S6 IR & 1064 & 700 & - \\
\hline
\end{tabular}

The dependence of the sensor responses on the hydrogen concentration between 0.2 and $2 \%$ is demonstrated in Figure 11, for deposition wavelengths of $532 \mathrm{~nm}$ and $1.06 \mu \mathrm{m}$, respectively. The sensitivity and limit of detection (LOD) for all sensors realized are also listed in Table 2. The noise level was estimated at $\sim 5 \mathrm{~Hz}$ for (S1, S5) and $\sim 10 \mathrm{~Hz}$ for (S2, S3, $\mathrm{S} 4, \mathrm{S6})$. The results indicate not only the importance of the $\mathrm{Pd} / \mathrm{ZnO}$ bilayer in comparison to a single layer of $\mathrm{ZnO}$, but also the importance of the morphology of the films that make up the bilayer, especially that of the $\mathrm{ZnO}$ film. 


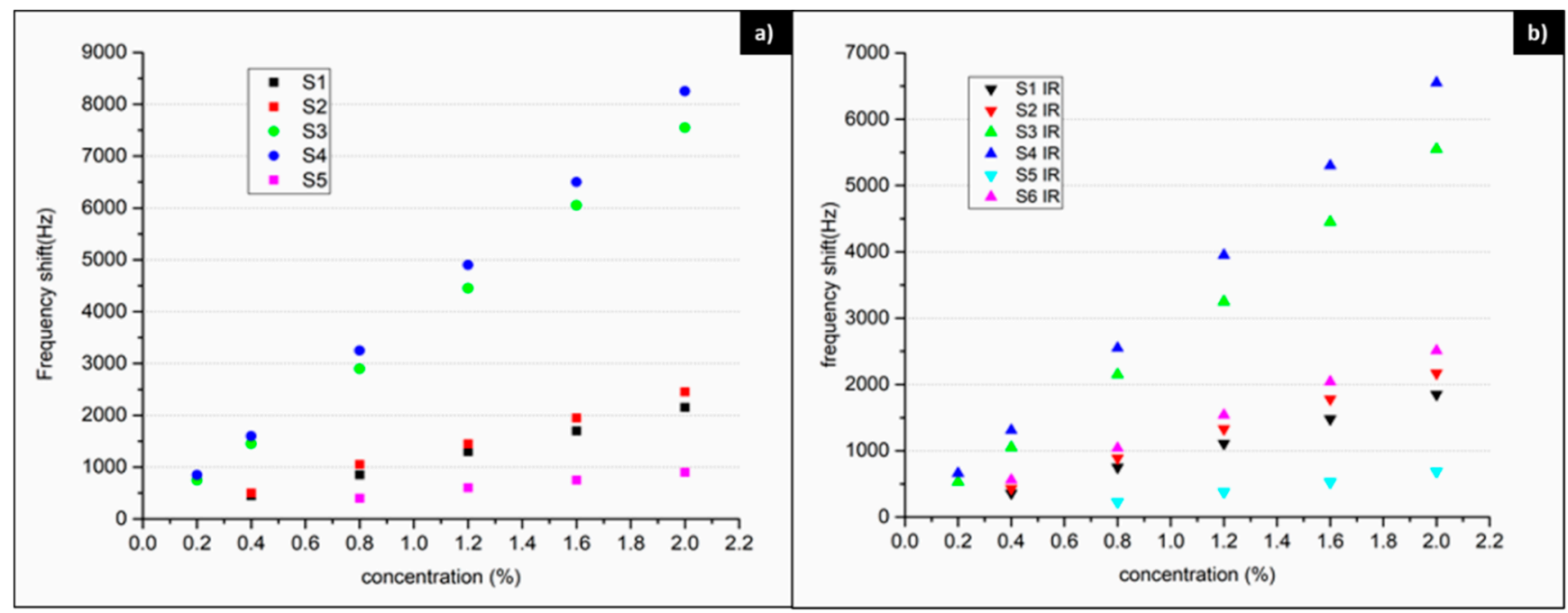

Figure 11. Sensor response to various $\mathrm{H}_{2}$ concentrations. (a) Sensitive films deposited with $532 \mathrm{~nm}$ laser radiation. (b) Sensitive films deposited with $1.06 \mu \mathrm{m}$ laser radiation.

Table 2. Sensitivity and limit of detection (LOD) of the sensors. Legend: $\Delta \mathrm{f}$-frequency change; $\mathrm{c}$-hydrogen concentration; $n$-noise level.

\begin{tabular}{|c|c|c|c|c|c|}
\hline \multicolumn{4}{|c|}{$532 \mathrm{~nm}$} & \multicolumn{2}{|c|}{$1064 \mathrm{~nm}$} \\
\hline Sensor & $\begin{array}{c}\text { Sensitivity }(\Delta \mathrm{f} / \mathrm{c}) \\
(\mathrm{Hz} / \mathrm{ppm})\end{array}$ & $\begin{array}{c}\operatorname{LOD}(3 \times n) /(\Delta \mathrm{f} / \mathrm{c}) \\
(\mathrm{ppm})\end{array}$ & Sensor & $\begin{array}{c}\text { Sensitivity }(\Delta \mathrm{f} / \mathrm{c}) \\
(\mathrm{Hz} / \mathrm{ppm})\end{array}$ & $\begin{array}{c}\operatorname{LOD}(3 \times n) /(\Delta \mathrm{f} / \mathrm{c}) \\
(\mathrm{ppm})\end{array}$ \\
\hline S1 & 0.108 & 138.67 & S1 IR & 0.0923 & 162.6 \\
\hline $\mathrm{S} 2$ & 0.124 & 241.37 & S2 IR & 0.1099 & 273.06 \\
\hline S3 & 0.371 & 80.85 & S3 IR & 0.2705 & 110.93 \\
\hline $\mathrm{S} 4$ & 0.41 & 73.22 & S4 IR & 0.3274 & 91.64 \\
\hline \multirow[t]{2}{*}{ S5 } & 0.048 & 312.7 & S5 IR & 0.032 & 468.6 \\
\hline & & & S6 IR & 0.1303 & 230.3 \\
\hline
\end{tabular}

The sensors having a sensitive layer of $\mathrm{ZnO}$ only and those with $\mathrm{Pd} / \mathrm{ZnO}$ bilayers, with the $\mathrm{ZnO}$ deposited in 100 mTorr oxygen, did not respond to low hydrogen concentrations. The difference in the response of sensors containing $\mathrm{ZnO}$ deposited at higher oxygen pressure, which are more porous, from those deposited in 100 mTorr oxygen is clearly visible, the porous films leading to a larger response, higher sensitivity and lower LOD. The relative difference between the response of sensors having $\mathrm{ZnO}$ layers deposited in $100 \mathrm{mTorr}$ and $700 \mathrm{mTorr} \mathrm{O}_{2}$ is $66-70 \%$ for all hydrogen concentrations investigated, regardless of the overlying Pd layer properties or the laser wavelength used. This indicates the importance of the porosity of the $\mathrm{ZnO}$ layer in determining the SAW sensor response. The influence of the Pd layer morphology, on the other hand, is less evident, with the relative difference in the frequency shifts for sensors with Pd layers deposited in 100 or 700 mTorr Ar on top of $\mathrm{ZnO}$ layers deposited in identical conditions being only in the range of $12-20 \%$. This is to be expected since the morphology of the thin Pd layers deposited at the higher and lower pressures used in the sensors is not qualitatively different, as the SEM results presented have shown. However, it is worth mentioning that it is always the $\mathrm{Pd}$ layers deposited at higher pressure that produce better results. The presence of a Pd layer on top of $\mathrm{ZnO}$ leads to a significant improvement in the sensor response in comparison to a $\mathrm{ZnO}$ layer only, as we have shown in previous research, as well [25]. The results given in the present paper indicate that the morphology of the $\mathrm{ZnO}$ component of the bilayer has an influence on the sensor properties of the same order as the influence of the presence of the Pd layer.

Regarding the dependence of sensor properties on the wavelength of the radiation used, the $532 \mathrm{~nm}$ wavelength leads to somewhat better results than the infrared wavelength, 
as can be seen by comparing Figure $10 a, b$ (note the difference in vertical scale). This can be explained by the morphological differences in Figure 5, namely that the films deposited at $532 \mathrm{~nm}$ seem to have a larger density of porous formations than the ones deposited at $1.06 \mu \mathrm{m}$.

\section{Conclusions}

Previous research has indicated that a $\mathrm{Pd} / \mathrm{ZnO}$ bilayer leads to improved SAW sensor properties compared to single $\mathrm{Pd}$ or $\mathrm{ZnO}$ layers [25]. The present paper describes results regarding the contribution of the morphology of the $\mathrm{ZnO}$ and $\mathrm{Pd}$ thin film components of the bilayer to the sensor response. These results were obtained using an important advantage of PLD, namely the relative ease with which the morphology of the layers can be controlled through variation of the laser deposition parameters.

For both materials studied, as has been previously observed for other materials [16], higher deposition pressures led to more porous films. Larger porosities are also obtained in the case of thicker films and in those obtained with a larger energy per pulse. Regarding the dependence on the laser wavelength, $\mathrm{ZnO}$ films deposited using $532 \mathrm{~nm}$ have a larger density of porous formations than those deposited with IR radiation. Although comparison between lasers with ns and ps pulse duration are difficult due to differences in other parameters, $\mathrm{ZnO}$ depositions using ps pulse durations were, in the cases studied by us, considerably more porous than those obtained with ns pulses at the same deposition pressure.

The differences in the porosity of the films affect the responses of the SAW sensors into which they are incorporated, with the deposition conditions producing more porous films leading to a larger sensor response. The morphology of the $\mathrm{ZnO}$ component of the bilayer is decisive, with films deposited in 700 mTorr $\mathrm{O}_{2}$ using $532 \mathrm{~nm}$ having the largest responses (largest frequency shifts for a given hydrogen concentration). The effect of the $\mathrm{Pd}$ film morphology, although present, is smaller than that of $\mathrm{ZnO}$, probably due to the smaller film thickness. However, the results obtained with Pd films deposited at higher pressures are systematically slightly better than those obtained at lower Ar pressures.

The main result of the research presented here is that the morphology of the $\mathrm{ZnO}$ component of the sensitive layer incorporated into the SAW sensor has an influence on the sensor properties of the same order of magnitude as the use of a bilayer instead of a simple $\mathrm{Pd}$ or $\mathrm{ZnO}$ layer. This could have implications in other bilayer material combinations used in such sensors and for other types of analytes.

Supplementary Materials: The following are available online at https: / www.mdpi.com/article / 10.3390/nano11102598/s1.

Author Contributions: Conceptualization, D.M. and C.V.; methodology, D.M., C.E. and I.C.; formal analysis, D.M.; investigation, I.C. and C.V.; writing-original draft preparation, D.M.; writingreview and editing, I.C.; funding acquisition, C.V. All authors have read and agreed to the published version of the manuscript.

Funding: This work was supported by a grant from the Romanian Ministry of Education and Research, CNCS-UEFISCDI, project number PN-III-P1-1.1-TE-2019-0573.

Institutional Review Board Statement: Not applicable.

Informed Consent Statement: Not applicable.

Data Availability Statement: Not applicable.

Acknowledgments: The authors wish to thank Flaviu Baiasu for the XRD analysis.

Conflicts of Interest: The authors declare no conflict of interest. 


\section{References}

1. Xu, H.; Liu, Y.; Liu, H.; Dong, S.; Wu, Y.; Wang, Z.; Wang, Y.; Wu, M.; Han, Z.; Hao, L. Pd-decorated 2D SnSe ultrathin film on $\mathrm{SiO}_{2} / \mathrm{Si}$ for room-temperature hydrogen detection with ultrahigh response. J. Alloy. Compd. 2020, 851, 156844. [CrossRef]

2. Li, Z.; Yao, Z.; Haidry, A.A.; Plecenik, T.; Xie, L.; Sun, L.; Fatima, Q. Resistive-type hydrogen gas sensor based on TiO2: A review. Int. J. Hydrog. Energy 2018, 43, 21114-21132. [CrossRef]

3. Okolie, J.A.; Patra, B.R.; Mukherjee, A.; Nanda, S.; Dalai, A.K.; Kozinski, J.A. Futuristic applications of hydrogen in energy, biorefining, aerospace, pharmaceuticals and metallurgy. Int. J. Hydrog. Energy 2021, 46, 8885-8905. [CrossRef]

4. Chen, K.; Yuan, D.; Zhao, Y. Review of optical hydrogen sensors based on metal hydrides: Recent developments and challenges. Opt. Laser Technol. 2020, 137, 106808. [CrossRef]

5. Liu, W.; Zuo, H.; Wang, J.; Xue, Q.; Ren, B.; Yang, F. The production and application of hydrogen in steel industry. Int. J. Hydrog. Energy 2021, 46, 10548-10569. [CrossRef]

6. Kima, J.-H.; Mirzaei, A.; Kim, H.W.; Kim, S.S. Improving the hydrogen sensing properties of $\mathrm{SnO}_{2}$ nanowire-based conductometric sensors by Pd-decoration. Sens. Actuators B. Chem. 2019, 285, 358-367. [CrossRef]

7. Nikolaeva, N.S.; Klyamer, D.D.; Zharkov, S.M.; Tsygankova, A.R.; Sukhikh, A.S.; Morozova, N.B.; Basova, T.V. Heterostructures based on PdeAu nanoparticles and cobalt phthalocyanine for hydrogen chemiresistive sensors. Int. J. Hydrog. Energy 2021, 46, 19682-19692. [CrossRef]

8. Wang, W.; Liu, X.; Mei, S.; Jia, Y.; Liu, M.; Xue, X.; Yang, D. Deveopment of Pd/Cu nanowires coated SAW hydrogen gas sensor with fast response and recovery. Sens. Actuators B Chem. 2019, 287, 157-164. [CrossRef]

9. Constantinoiu, I.; Viespe, C. Hydrogen Detection with SAW Polymer/Quantum Dots Sensitive Films. Sensors 2019, 19 , 4481. [CrossRef]

10. Ballantine, D.S.; White, R.M.; Martin, S.J.; Ricco, A.J.; Zellers, E.T.; Frye, G.C.; Wohtjen, H. Acoustic Wave Sensors, Theory, Design and Physico-Chemical Applications; Academic Press: San Diego, CA, USA, 1997.

11. Panneerselvam, G.; Thirumal, V.; Pandya, H.M. Review of Surface Acoustic Wave Sensors for the Detection and Identification od Toxic Environmental Gases/Vapours. Arch. Acoust. 2018, 43, 357-367.

12. Kus, F.; Altinkok, C.; Zayim, E.; Erdemir, S.; Tasaltin, C.; Gurol, I. Surface acoustic wave (SAW) sensor for volatile organic compounds (VOCs) detection with calix[4]arene functionalized Gold nanorods (AuNRs) and silver nanocubes (AgNCs). Sens. Actuators B Chem. 2020, 330, 129402. [CrossRef]

13. Matatagui, D.; Gràcia, I.; Horrillo, M. Response of a SAW Sensor Array based on Nanoparticles for Measuring Ammonia in the Environment. In Proceedings of the 9th International Conference on Sensor Networks-SENSORNETS, Valletta, Malta, 28-29 February 2020; pp. 93-99, ISBN 978-989-758-403-9. [CrossRef]

14. Tanga, Y.; Xu, X.; Han, S.; Cai, C.; Du, H.; Zhu, H.; Zu, X.; Fu, Y. ZnO- $\mathrm{Al}_{2} \mathrm{O}_{3}$ nanocomposite as a sensitive layer for high performance surface acoustic wave $\mathrm{H}_{2} \mathrm{~S}$ gas sensor with enhanced elastic loading effect. Sens. Actuators B. Chem. 2020, $304,127395$. [CrossRef]

15. Harathi, N.; Kavitha, S.; Sarkar, A. ZnO nanostructured 2D layered SAW based hydrogen gas sensor with enhanced sensitivity. Mater. Today Proc. 2020, 33, 2621-2625. [CrossRef]

16. Constantinoiu, I.; Viespe, C. Development of $\mathrm{Pd} / \mathrm{TiO}_{2}$ Porous Layers by Pulsed Laser Deposition for Surface Acoustic Wave H2 Gas Sensor. Nanomaterials 2020, 10, 760. [CrossRef] [PubMed]

17. Constantinoiu, I.; Miu, D.; Viespe, C. Surface Acoustic Wave Sensors for Ammonia Detection at Room Temperature Based on $\mathrm{SnO}_{2} / \mathrm{Co}_{3} \mathrm{O}_{4}$ Bilayers. J. Sens. 2019, 2019, 1-6. [CrossRef]

18. Sima, C.; Viespe, C. Surface Acoustic Wave Sensors Based on Nanoporous $\mathrm{SnO}_{2}$ Films for Hydrogen Detection; Chemical Sensors and Biosensors: Barcelona, Spain, 2018.

19. Ozturk, S.; Kilimc, N. Pd thin films on flexible substrate for hydrogen sensor. J. Alloy. Compd. 2016, 674, 179-184. [CrossRef]

20. Li, D.; Le, X.; Pang, J.; Peng, L.; Xu, Z.; Gao, C.; Xie, J. A SAW hydrogen sensor based on decoration of graphene oxide by palladium nanoparticles on AIN/Si layered structure. J. Micromech. Microeng. 2019, 29, 45007. [CrossRef]

21. Groenen, R.; Smit, J.; Orsel, K.; Vailionis, A.; Bastiaens, H.M.; Huijben, M.; Boller, K.J.; Rijnders, A.J.; Koster, G. Research update: Stoichiometry controlled oxide thin film growth by pulsed laser deposition. APL Mater. 2015, 3, 70701. [CrossRef]

22. Cheng, P.; Wang, L.; Pan, Y.; Yan, H.; Gao, D.; Wang, J.; Zhang, H. Fiber Bragg grating temperature sensor of cladding with $\mathrm{SrTiO}_{3}$ thin film by pulsed laser deposition. Laser Phys. 2019, 29, 25107. [CrossRef]

23. Slaiby, Z.E.; Ramizy, A. Synthesis gallium nitride thin films by pulsed laser deposition as ammonia $\left(\mathrm{NH}_{3}\right)$ gas sensor. $J$. Optoelectron. Biomed. Mater. 2020, 12, 17-23.

24. Dekic, M.; Salcinovic Fetic, A.; Hrvat, K.; Lozancic, M. Influence of deposition parameters on pulsed laser deposition of $\mathrm{K}_{0.3} \mathrm{MoO}_{3}$ thin films. Bull. Chem. Technol. Bosnia Herzeg. 2017, 48, 1-4.

25. Viespe, C.; Miu, D. Surface Acoustic Wave Sensor with Pd/ZnO Bilayer Sructure for Room Temperature Hydrogen Detection. Sensors 2017, 17, 1529. [CrossRef]

26. Sanger, A.; Kumar, A.; Kumar, A.; Jaiswal, J.; Chandra, R. A fast response/recovery of hydrophobic $\mathrm{Pd} / \mathrm{V}_{2} \mathrm{O}_{5}$ thin films for hydrogen gas sensing. Sens. Actuators B Chem. 2016, 236, 16-26. [CrossRef]

27. Miu, D.; Birjega, R.; Viespe, C. Surface Acoustic Wave Hydrogen Sensors Based on Nanostructured Pd/WO 3 Bilayers. Sensors 2018, 18, 3636. [CrossRef] 
28. Viespe, C.; Miu, D. Characteristics of Surface Acoustic Wave Sensors with Nanoparticles Embedded in Polymer Sensitive Layers for VOC Detection. Sensors 2018, 18, 2401. [CrossRef] [PubMed]

29. Image J Open-Source Image Processing Program; NIH: Bethesda, MD, USA, 2008.

30. Geohegan, D.B.; Puretzky, A.A. Laser ablation plume thermalization dynamics in background gases: Combined imaging, optical absorption and emission spectroscopy, and ion probe measurements. Appl. Surf. Sci. 1996, 96-98, 131-138. [CrossRef]

31. Harilal, S.S.; O'Shay, B.; Tao, Y.; Tillack, M.S. Ambient gas effects on the dynamics of laser-produced tin plume expansion. J. Appl. Phys. 2006, 99, 83303. [CrossRef]

32. Geohegan, D.; Puretzky, A.; Duscher, G.; Pennycook, S.J. Time-resolved imaging of gas phase nanoparticle synthesis by laser ablation. Appl. Phys. Lett. 1998, 72, 2987-2989. [CrossRef]

33. Tillack, M.S.; Blair, D.W.; Harilal, S.S. The effect of ionization on cluster formation in laser ablation plumes. Nanotechnology 2004, 15, 390-403. [CrossRef]

34. Viespe, C.; Dinca, V.; Popescu-Pelin, G.; Miu, D. Love Wave Surface Acoustic Wave Sensor with Laser-Deposited Nanoporous Gold Sensitive Layer. Sensors 2019, 19, 4492. [CrossRef] [PubMed] 